\title{
Bioturbation and irrigation in natural sediments, described by animal-community parameters
}

\author{
Joanna Sandnes ${ }^{1}$, Thomas Forbes ${ }^{2}$, Rikke Hansen ${ }^{3}$, Bjørnar Sandnes ${ }^{4, *}$, Brage Rygg ${ }^{1}$ \\ ${ }^{1}$ Norwegian Institute for Water Research (NIVA), PO Box 173 Kjelsås, 0411 Oslo, Norway \\ ${ }^{2}$ Department of Marine Ecology, National Environmental Research Institute, PO Box 358, Frederiksborgvej 399, \\ 4000 Roskilde, Denmark \\ ${ }^{3}$ Darling Marine Center, University of Maine, Walpole, Maine 04573, USA \\ ${ }^{4}$ Department of Physics, University of Oslo, PO Box 1048 Blindern, 0316 Oslo, Norway
}

\begin{abstract}
The key objective of this study was to compare tracer-based methods that measure bioturbation and irrigation rates with predictive models based on benthic community parameters such as animal size and abundance. The individual parameters of each model were investigated separately to assess their relative influence on model output. An important aspect of this study was its focus on benthic processses in natural marine sediments, where the well-defined model assumptions are not necessarily accomodated. Faunal parameters were incorporated into a biodiffusion model proposed to describe bioturbation, and direct comparisons were made to tracer-based depth distributions of an inert particle tracer, ${ }^{51} \mathrm{Cr}$. The results showed that this biodiffusion model under-estimated bioturbation rates $\left(D_{\mathrm{b}}\right)$ compared to ${ }^{51} \mathrm{Cr}$ tracer measurements. It was shown that the model predictions were highly sensitive to estimates of faunal weight and sediment reworking depth. The model suggests that large, deposit-feeding animals dominate biogenous mixing and that mixing rates are more influenced by animal size than density. In the box-cosm system, the Iarge urchins Echinocardium cordatum did in fact dominate sediment-mixing processes. Irrigation was modelled by a combination of the non-local transport model and the radial-diffusion model, using animal size and density, and was compared to downcore distributions of a dissolved, conservative tracer bromide $\left(\mathrm{Br}^{-}\right)$. Modelled irrigation rates increased as a function of burrow radius and animal density, with the strongest dependency on animal density. Given the simplicity of the assumptions for the idealized radial-diffusion model, agreement between measured and predicted rates was relatively good in $50 \%$ of the box-cosms. Over-estimation in the remainder may be attributable to unrealistic assumptions that all individuals inhabit vertical burrows and irrigate them continuously.
\end{abstract}

KEY WORDS: Bioturbation - Irrigation · Benthos $\cdot$ Sediment $\cdot$ Infaund $\cdot$ Models $\cdot$ Tracers

\section{INTRODUCTION}

The physical and chemical properties of marine deposits are profoundly influenced by the activities of benthic organisms and the biogenic structures they produce (Aller 1980, Boudreau \& Marinelli 1994, Gerino et al. 1998). Benthic activities such as feeding, burrowing and irrigation result in particle and fluid transport near the sediment-water interface, a critical boundary zone for diagenetic reactions (Aller 1980, Yingst \& Rhoads 1980 ,

·Corresponding author. E-mail: bsand@fys.uio.no
Kristensen 1988). Effects of these activities on sediment properties are well documented; they influence redox levels, organic matter and contaminant-degradation rates, dissolution of biogenic compounds $\left(\mathrm{CaCO}_{3}\right.$ and $\mathrm{SiO}_{2}$ ), nutrient fluxes, pore-water profiles and microbial activity (Yingst \& Rhoads 1980, Aller 1982, Boudreau 1998, Kristensen 1988, Gerino et al. 1998). The need to account quantitatively for these effects has resulted in the development of different types of models to predict mixing of particulate sediment (Crank 1975, Berner 1980, Wheatcroft et al. 1990) and to characterize the geochemistry of ventilated sediments (Aller 1980, Boudreau 1984, Emerson et al. 1984). 
Bioturbation, or particle-mixing, is the mechanical disturbance of benthic sediments. It is recognised as one of the major processes altering the structure of sedimentary deposits over vast spatial scales (Gerino et al. 1998), resulting in both the reworking of particles and pore-water transport (Powilleit et al. 1994). Typical estimates of sediment particle mixing by tracers are expressed as biodiffusion rates $\left(D_{\mathrm{b}}\right)$ that incorporate all animal activities affecting the sediment (e.g. depositfeeding, burrows, tube-building) into a single coefficient. In so doing, the specific mechanisms driving such processes are masked, thereby reducing the predictive understanding of bioturbation (Wheatcroft et al. 1990). A biodiffusion model has been developed by Wheatcroft et al. in an attempt to bridge this gap by using parameters directly from the animal community to predict sediment-mixing rates in marine environments.

Sediment irrigation is the advection of overlying water across the sediment-water interface and through infaunal burrow systems. Several different methods have been applied to estimate sediment irrigationrates experimentally; these include the analysis of pore-water profiles in closed-system sediment incubations (Christensen et al. 1984), fluxes, and porewater profiles of tracers believed to be unreactive, or those with known reactive rates (Key et al. 1979, Martin \& Sayles 1987). The effects of infauna on solute exchange across the sediment-water interface have been modelled using 2 different approaches. The first consists of a term for diffusion and a separate non-local exchange term describing infaunal irrigation that is determined empirically and therefore does not explain the underlying faunal processes (Emerson et al. 1984). The second approach, developed by Aller (1980), characterizes a microenvironment in the bioturbated zone represented by finite hollow cylinders equivalent to burrow structures. It incorporates information on the size and density of infaunal burrows into model predictions, thereby giving a more realistic mathematical representation of irrigation and its effects on sediment geochemistry (Boudreau \& Marinelli 1994).

The key objective of this study was to compare tracer-based methods that measure bioturbation and irrigation rates with predictive models based on benthic community parameters such as animal size and abundance. Faunal parameters were incorporated into the biodiffusion model proposed to describe bioturbation by Wheatcroft et al. (1990), and direct comparisons were made to tracer-based depth distributions of an inert particle tracer, ${ }^{51} \mathrm{Cr}$. Similarly for irrigation, a combination (Boudreau 1984) of the non-local transport model (Emerson et al. 1984) and the radial-diffusion model (Aller 1980), using animal size and density, were compared to down-core distributions of a dissolved, conservative tracer bromide $\left(\mathrm{Br}^{-}\right)$. The indivi- dual parameters of each model were investigated separately to assess their relative influence on model output. An important aspect of this study was its focus on benthic processses in natural marine sediments, where the well-defined model assumptions are not necessarily accomodated. It is in natural ecosystems that the application of such faunal-based models describing these benthic processes could be useful, for example in predicting the fate and transport of anthropogenic contaminants.

\section{MATERLALS AND METHODS}

The experimental box-cosm system consisted of 12 PVC box-cores $\left(0.25 \mathrm{~m}^{2}\right)$ of natural sediment collected in the Oslofjord at Haxytangen $\left(59^{\circ} 10^{\prime} \mathrm{N}\right.$, $10^{\circ} 36^{\prime} \mathrm{E}$ ), from a depth of 60 to $62 \mathrm{~m}$ in July 1996. A flow-through water system with a header tank supplied unfiltered seawater continuously at a constant rate of $\sim 0.5 \mathrm{l} \mathrm{min}^{-1}$ from $60 \mathrm{~m}$ depth at Solbergstrand, Oslofjord. A constant seawater temperature and salinity of $8.8 \pm 0.4^{\circ} \mathrm{C}$ and $34.5 \pm 0.3 \%$, respectively, were recorded automatically for the duration of the experiment.

All 12 box-cosms received the same pulse addition of ${ }^{51} \mathrm{Cr}$-labelled sediment and phytoplankton particles, which was carefully distributed onto the sediment surface to form a 1 to $2 \mathrm{~mm}$ layer (see Sandnes et al, 2000 [in this issue] for further details of the experimental box-cosm system and design.)

\section{Sampling the experimental system}

${ }^{51}$ Cr sediment profiles. Final sediment cores, 3 replicates per box-cosm, were taken on Day 48. The corers consisted of $8 \mathrm{~cm}$ diam. acrylic cylinders. Each core was sectioned into $0.5 \mathrm{~cm}$ slices in the upper $2 \mathrm{~cm}$, then by $1 \mathrm{~cm}$ sections to $4 \mathrm{~cm}$, and in $2 \mathrm{~cm}$ intervals down to $8 \mathrm{~cm}$. Known amounts of sediment were transfered to $5 \mathrm{ml}$ gamma vials and measured for ${ }^{51} \mathrm{Cr}$ content (Packard Instruments, Cobra II).

Bromide incubations. Triplicate bromide $\left(\mathrm{Br}^{-}\right)$incubations were implemented for each box-cosm at the end of the experimental period. Three acrylic corers of $8 \mathrm{~cm}$ diam. were positioned in each box-cosm. The corers were depressed into the sediment to a premarked level that indicated a 11 water volume above the sediment surface. $\mathrm{NaBr}$ was added to the enclosed 11 seawater to create a $\mathrm{Br}^{-}$water concentration of $-10 \mathrm{mM}$ compared to ambient concentrations of $\sim 0.8 \mathrm{mM}$. The overlying water was stirred, the corer sealed with a rubber cork, and incubated for $\sim 24 \mathrm{~h}$. A relatively short $\mathrm{Br}^{-}$incubation time was used to min- 
imise the effects of sediment mixing that occurs over larger time scales.

The $8 \mathrm{~cm}$ diam. cores were removed and immediately sectioned, and the exact incubation time recorded. Each core was sectioned into $0.5 \mathrm{~cm}$ slices in the upper $2 \mathrm{~cm}$, followed by $1 \mathrm{~cm}$ sections to $4 \mathrm{~cm}$, and then $2 \mathrm{~cm}$ intervals down to $8 \mathrm{~cm}$. Porewater was separated from the sediments by centrifuging $(16100 \times g, 15 \mathrm{~min})$, and was used for the direct determination of $\mathrm{Br}^{-}$concentration by high-performance liquid chromatography (HPLC) (Gilson Unipoint HPLC System). Water samples were diluted $\times 100$ in Milli- $Q$ water, a $20 \mu \mathrm{l}$ subsample of which was analysed. Chromatographic separations were performed with a mobile phase consisting of potassium dihydrogen phosphate $\left(\mathrm{KH}_{2} \mathrm{PO}_{4}\right) /$ tetrabutyl ammonium hydroxide $\left(\mathrm{C}_{16} \mathrm{H}_{37} \mathrm{NO}_{2}\right)(10 \mathrm{mM}$ : $0.7 \mathrm{mM}$ ), pumped at a flow rate of $1.5 \mathrm{ml} \mathrm{min}^{-1}$ and a temperature of $50^{\circ} \mathrm{C}$, to an ODS $\mathrm{C}_{18}(250 \times 5 \mathrm{~mm}$ i.d. $)$ column. The effluent was monitored at $210 \mathrm{~nm}$ with a UV detector (Gilson), and the direct detection of $\mathrm{Br}^{-}$ was automatically recorded. Standard solutions were prepared using $\mathrm{NaCl}$ salts dissolved in Milli-Q water.

Animal-community analysis. Triplicate cores of $8 \mathrm{~cm}$ diam. were removed from all box-cosms at the end of the experimental period for animal community analysis. Each core was sieved through a $350 \mu \mathrm{m}$ mesh and preserved in formalin prior to identification. All individuals were identified, and size parameters (lengths, widths) were recorded. The urchin Echinocardium cordatum was the dominant species in terms of size in the boxcosm system, as reported by Sandnes et al. (2000). Hence, as an important macrofaunal component in the experimental system, all individuals were collected from each box-cosm at the end of the experimental period and size parameters (length, height, width) were measured.

\section{Modelling and statistical methods}

Biodiffusion $\left(D_{\mathrm{b}}\right)$ modelling. Biodiffusion coefficients $\left(D_{\mathrm{b}}\right)$ were estimated using animal community data (triplicate cores) from each box-cosm. This particulate biodiffusion coefficient can be decomposed into the fundamental dimensions of length and time (Wheatcroft et al. 1990):

$$
D_{\mathrm{b}}=\frac{L^{2}}{2 \Omega}
$$

where $L=$ distance of a particle step expressed as animal length, and $\Omega=$ mean rest period of particle. Estimates of animal ingestion rates were necessary to calculate the rest periods $(\Omega)$. Results of the study of Cammen (1980) showed that both body weight and concentration of organic matter in food were important factors in the prediction of ingestion rates of species.
Cammen summarised animal ingestion rate as a function of both body weight and organic matter in the simple regression equation:

$$
\log I=-0.362+0.771 \log W-0.92 \log O M
$$

where $I=$ total matter ingested $\left(\mathrm{mg} \mathrm{d}^{-1}\right), W=$ body weight $(\mathrm{mg})$, and $O M=$ fraction of organic material in the food. Size parameters of individual organisms from each replicate core were used to determine their volume by approximation to geometric shapes, and weights were subsequently obtained (density of $1.1 \mathrm{~g} \mathrm{~cm}^{-3}$ ). The weights of all individuals from each core were combined with urchin densities (box-cosm ${ }^{-1}$ ) to estimate the total ingestion rates $\left(\mathrm{mg} \mathrm{d}^{-1} \mathrm{~m}^{-2}\right.$ ). The organic carbon content of the sediment from individual box-cosms was measured and converted to organic matter $(O M)$ by multiplying by 1.9 (Bader 1954, Cammen 1980).

The mean particle rest period $(\Omega)$ was estimated by calculating the time interval between ingestion of the same particle. The total volume of reworked sediment (sediment available for ingestion) was divided by the calculated volume of sediment ingested by the animal community in each replicate core (density $=1.7 \mathrm{~g} \mathrm{~cm}^{-3}$ ) yielding estimates of $\Omega$ per day. The mean estimate of sediment depth reworked by the species within the box-cosm communities was based on the assumptions of the maximal sediment depth at which the animals occurred (Wheatcroft et al. 1990), assuming that most of the macrofauna inhabited the upper $4 \mathrm{~cm}$ sediment. Although the urchins are known to burrow generally between 2 and $7 \mathrm{~cm}$ depth (pers. obs.), the ${ }^{51} \mathrm{Cr}$ tracer results indicated no mixing below this $4 \mathrm{~cm}$ depth, and hence this was chosen as a reasonable mean estimate. $D_{\mathrm{b}}$ values were then determined by Eq. (1) using the calculated mean animal lengths $(L)$ and the rest periods $(\Omega)$ per replicate core (3 box-cosm ${ }^{-1}$ ) (Hansen et al. 1999).

$D_{\mathrm{b}}$ estimates obtained using this (Wheatcroft et al. 1990) model (Eq. 1) were compared to tracer-based ${ }^{5 t} \mathrm{Cr}$ experimental $D_{\mathrm{b}}$ estimates (Sandnes et al. 2000) by a paired Student's t-test. The paired differences in the data were normally distributed and therefore satisfied the assumption for this analysis.

Sediment irrigation modelling. Since bromide $\left(\mathrm{Br}^{-}\right)$ distribution is not affected by adsorption to sediment (Aller 1983), the distribution of $\mathrm{Br}^{-}$in pore-waters at time $t$ and depth $x$ can be described by the non-local transport model:

$$
\frac{\partial(\phi C)}{\partial t}=\phi \frac{\partial C}{\partial t}=\frac{\partial}{\partial x}\left(\phi D_{s} \frac{\partial C}{\partial x}\right)+\alpha \phi\left(C_{o / w}-C\right)
$$

(Emerson et al. 1984, Martin \& Banta 1992), with boundary conditions:

$$
C(x=0, t>0)=C_{0} / w
$$




$$
\begin{gathered}
\frac{\partial C}{\partial x}\left(x=x_{\max }, t>0\right)=0 \\
C(x, t=0)=C_{0}
\end{gathered}
$$

where $x_{\max }=$ maximum depth of the incubated sediment column, and $\mathrm{C}_{0}=$ initial distribution of excess $\mathrm{Br}^{-}$ in the pore-waters, and $C_{\mathrm{o} / \mathrm{w}}=$ concentration of excess $\mathrm{Br}^{-}$in the overlying water column after $\mathrm{NaBr}$ addition.

$\phi$ is sediment porosity, which is constant over time but varies exponentially with depth:

$$
\phi(x)=a+b e^{-c x}
$$

where parameters $a, b$ and $c$ were determined by leastsquares fit (quasi-Newton estimation method) to measured $\phi$ profiles.

The diffusion coefficient $\left(D_{\mathrm{s}}\right)$ of $\mathrm{Br}^{-}$in the natural box-cosm sediments was estimated using an abbreviated, diffusion-only form of Eq. (3) (last term not included), which was adjusted for tortuosity by incorporating the relationship

$$
D_{\mathrm{s}}(x)=\xi D_{\mathrm{sw}} \phi^{2}(\mathrm{x})
$$

where $D_{\mathrm{sw}}=$ diffusion coefficient at infinite dilution $\left(6.34 \times 10^{-2} \mathrm{~cm} \mathrm{~h}^{-1}\right)\left(\mathrm{Li} \&\right.$ Gregory 1974). $D_{\mathrm{s}}$ was determined by adjusting $D_{\mathrm{sw}}$ by a factor $\xi$ (estimated at 0.3 ) to produce the best fit (by eye) of the diffusion-only form of Eq. (3) to the mean $\mathrm{Br}^{-}$profiles in defaunated boxcosms. In this way, $D_{\mathrm{s}}$ served as an 'apparent' diffusion coefficient for the particular sediment in this study (T.F. et al. unpubl.).

Biologically driven sediment irrigation is described by the non-local exchange parameter $\alpha$ in Eq. (3), such that the rate of change over time of a pore-water solute concentration due to irrigation alone is given by the last term in this equation. This term describes the exchange of pore-water from any depth with the overlying water (Boudreau 1984).

An alternative method of assessing irrigation rates involves the use of parameters from the faunal community and sediment properties. A mathematical representation of biologically-driven irrigation using animal parameters is Aller's (1980) radial-diffusion model, which assumes that specific changes in the average geometry of molecular diffusion result from the presence of irrigated burrow and tube structures (Aller 1980). In this model, irrigated sediment is idealized as a collection of packed, regular, hollow cylinders (Fig. 1). The 'centre hollow' portion represents the tube or burrow, and contains continuously irrigated water. The annular region surrounding this cylinder is the lateral sediment region, and its chemistry is directly affected by burrow irrigation (Aller 1980, Boudreau \& Marinelli 1994).

Boudreau (1984) has shown that the radial-diffusion model of Aller (1980) can be reduced to the non-local transport model of Eq. (3). This allows the non-local term $\alpha$ to be expressed in terms of animal community parameters (abundance and size) originating from the radial-diffusion model:

$$
\alpha(x)=\frac{D_{s}(x) r_{1}}{\left(r_{2}^{2}-r_{1}^{2}\right)\left(r^{*}-r^{1}\right)}
$$

where $r_{1}=$ average burrow radius calculated from the mean animal widths $(\mathrm{cm}), r_{2}=$ average distance between burrow axes (cm) calculated as $r_{2}=1 / \sqrt{ } \pi N$ (Aller 1980; where $N$ is the faunal abundance $\left[\mathrm{cm}^{-2}\right]$ ), and $r^{*}=$ radial distance at which average bromide concentration $C(x, t)$ occurs at a particular depth and time (approximated by $\left[r_{2}-r_{1}\right] / 2$ ). Conditions of this model included:

$$
\begin{aligned}
& \frac{\partial C}{\partial r}=0 \text { for } \quad r=r_{2} \\
& C=C_{\mathrm{o} / \mathrm{w}} \text { for } \quad r=r_{1}
\end{aligned}
$$

Condition (6a) states that pore-water $\mathrm{Br}^{-}$concentrations reach a minimum at the average half distance between burrows, and (6b) assumes that concentrations at the burrow water/sediment interface are identical to those of the overlying water.

Substituting $D_{\mathrm{s}}$ from Eq. (5) and sediment porosity (Eq. 4) into $\alpha$ gives

$\alpha(x)=\xi D_{\mathrm{sw}} \phi^{2}(x) R=\xi D_{\mathrm{sw}}\left(a^{2}+2 a b \mathrm{e}^{-c x}+b^{2} \mathrm{e}^{-2 c x}\right) R$

where

$$
R=\frac{r_{1}}{\left(r_{2}^{2}-r_{1}^{2}\right)\left(r^{*}-r^{1}\right)}
$$

values for burrow radius, $r_{1}$, distance between burrows, $I_{2}$, and $r^{*}=\left(r_{2}-r_{1}\right) / 2$, measured for each boxcosm (triplicates), were used to calculate one $R$ per box-cosm. The resulting $\alpha$ (Eq. 7) (including $\phi$ data per box) was substituted into Eq. (3), which was solved numerically as a transient-state problem using the Galerkin finite-element method (Segerlind 1984). The resulting theoretical depth-profiles were compared to the measured $\mathrm{Br}^{-}$tracer profiles for each box-cosm.

Adjustments were made for the urchins to fit into the radial-diffusion model, as the ventillation burrows that they construct are considerably smaller than body widths. An estimated burrow radius of $1 \mathrm{~mm}$ was therefore used for these urchins when calculating $r_{1}$. Results did however show that because of low urchin densities, the choice of burrow radius did not significantly influence the average $r_{1}$ value of the box-cosm. Variations in experimental incubation times between box-cosms were incorporated into the model simulations. During the $\mathrm{Br}^{-}$incubations, the overlying water was stirred only once, and highly variable final $\mathrm{Br}^{-}$ concentrations in the overlying water samples sug- 
A
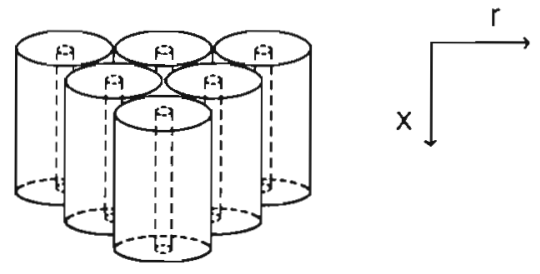

B

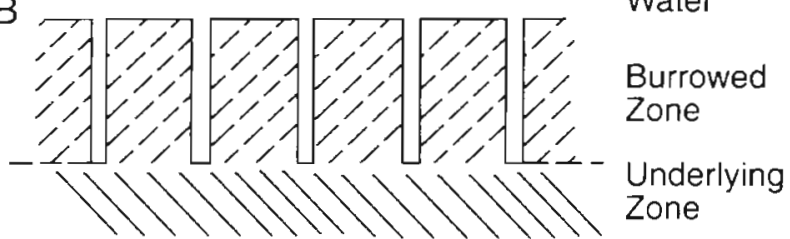

C

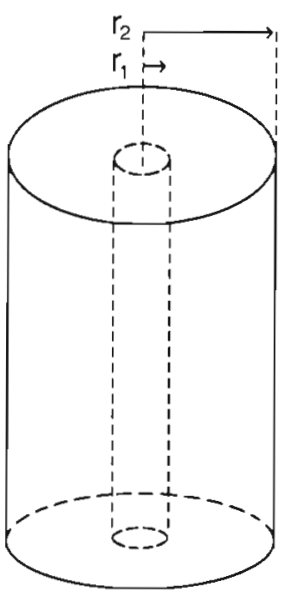

Fig. 1. (A) Sketch of upper region of burrowed sediment idealized as packed hollow cylinders; $(B)$ vertical cross-section of sediments with idealized diffusion geometry of $(\mathrm{A})$; (C) single hollow cylinder visualized as average microenvironment within bioturbated zone (source: Aller 1980 \} gested incomplete mixing of the tracer in the water column. Thus overlying water concentrations $\left(C_{0 / w}\right)$ were approximated by the surface $0.5 \mathrm{~cm}$ pore-water $\mathrm{Br}^{-}$ concentrations.

\section{RESULTS AND DISCUSSION}

\section{Biodiffusion $\left(D_{\mathrm{b}}\right)$ modelling}

Results showed an under-estimation of $D_{\mathrm{b}}$ values calculated using the Wheatcroft et al. (1990) model based on animal parameters (Eq. 1) from all box-cosms compared to tracer-based ${ }^{51} \mathrm{Cr}$ measurements $(9$-fold \pm 7 ) (Table 1). The sensitivity of this ingestion-based model to input variables, and its assumptions will be discussed in the following section in the light of this result. Biodiffusion in the model of Wheatcroft et al. is based on movements of particles by ingestion processes, and is modelled using estimates of particle rest-periods and step lengths.

\section{Rest period $(\Omega)$ estimation}

$\Omega$ is the time elapsed between particle movements, and was calculated in this study using parameters from the box-cosms' faunal communities and sediment. To illustrate how $D_{\mathrm{b}}$ rates were affected by fluctuations in $\Omega$ in the box-cosm system, the 3 replicate cores from one random box-cosm (Box-cosm 3) was used to calculate mean $\pm 95 \% \mathrm{CI}$. The $\Omega$ durations ranged from 151 to $357 \mathrm{~d}$, with resulting $D_{b}$ values ranging from 0.89 to $2.49 \mathrm{~cm}^{2} y^{-1}$ when $\Omega$ was stretched to $95 \% \mathrm{lim}$ its. This range did not however include the measured $D_{\mathrm{b}}$ value for this box-cosm from the tracer-based method $\left(4.5 \pm 0.7 \mathrm{~cm}^{2} \mathrm{yr}^{-1}\right)$.
Key parameters in assessing rest period $(\Omega)$ estimates

$\Omega$ depends not only on input for the total volume of sediment reworked, but also on ingestion rates, which are in turn a function of both animal weight and organic content of the food. The total volume of sediment reworked is clearly difficult to determine at a community level. It is directly related to the sedimentmixing depth, which in this study was estimated as $4 \mathrm{~cm}$ (determined from assumptions of maximal sediment depth of occurrence of the animals and tracer activity depth). Given the under-estimation of the $D_{\mathrm{b}}$ values, theoretical sediment-reworking depths were calculated to fit the experimental ${ }^{51} \mathrm{Cr}$ tracer-based measurements for each box-cosm, assuming all other parameters to be constant. The results showed that sediment-depth input values would be in the range of 0.2 to $2.4 \mathrm{~cm}$. This varied as a function of the inhabiting animal community in terms of abundance and size, and illustrates possible difficulties in standardising this parameter. The relationship between sediment depth and $D_{\mathrm{b}}$ is presented for Box-cosm 3 in Fig. 2, which illustrates the increased sensitivity of this parameter at lower sediment reworking depths when estimating sediment biodiffusion using the faunal-based model, Eq. (1) (Wheatcroft et al. 1990).

Estimation of ingestion rates is central in determining $\Omega$ estimates. If it is assumed that the volume of sediment reworked was correctly estimated in the present study, as indicated by the tracer data (Sandnes et al. 2000), an under-estimation of total sediment ingested occurred. In view of the high variance that occurs at larger body weights (Eq. 2) because of the log-log relationship between ingestion rate and weight, this discrepancy may partly be explained by the presence of large urchins in the benthic community. This is illustrated in Fig. 3 using data from Box-cosm 3 ingestion rate, $I$, is plotted 
Table 1. Biodiffusion rates $\left(D_{\mathrm{b}}\right)$ estimated using animal parameters in an ingestion-based model (Wheatcroft et al. 1990) and measurements of an inert tracer, ${ }^{51} \mathrm{Cr}$ (Sandnes et al. 2000). Total community ingestion, rest periods and animal abundance for faunal-based model are also shown

\begin{tabular}{|c|c|c|c|c|c|c|}
\hline \multirow[t]{2}{*}{$\begin{array}{l}\text { Box-cosm } \\
\text { no. }\end{array}$} & \multirow{2}{*}{$\begin{array}{l}\text { Total community } \\
\text { ingestion } \\
\left(\mathrm{mg} \mathrm{d}^{-1} \mathrm{~m}^{-2}\right)\end{array}$} & \multirow[t]{2}{*}{$\begin{array}{l}\text { Rest period }(\Omega) \\
\text { (d) }\end{array}$} & \multirow{2}{*}{$\begin{array}{l}\text { Total animal } \\
\text { abundance } \\
\left(\mathrm{m}^{-2}\right)\end{array}$} & \multirow{2}{*}{$\begin{array}{c}D_{\mathrm{b}} \text { estimate from } \\
\text { animal data } \\
\left(\mathrm{cm}^{2} \mathrm{yr}^{-1}\right)\end{array}$} & \multicolumn{2}{|c|}{$\begin{array}{c}\text { Box-cosm } D_{\mathrm{b}}\left(\text { mean } \pm \mathrm{SD} ; \mathrm{cm}^{2} \mathrm{yr}^{-1}\right) \\
\text { estimated from: }\end{array}$} \\
\hline & & & & & animal data & ${ }^{51} \mathrm{Cr}$-tracer data \\
\hline \multirow[t]{3}{*}{1} & 99704 & 682 & 17918 & 0.15 & $0.22 \pm 0.06$ & $2.55 \pm 1.83$ \\
\hline & 131802 & 516 & 17918 & 0.27 & & \\
\hline & 133491 & 509 & 28465 & 0.24 & & \\
\hline \multirow[t]{3}{*}{3} & 450058 & 151 & 25504 & 1.74 & $1.44 \pm 0.86$ & $4.54 \pm 0.70$ \\
\hline & 190801 & 356 & 19932 & 0.65 & & \\
\hline & 285299 & 238 & 20728 & 1.94 & & \\
\hline \multirow[t]{3}{*}{4} & 138875 & 490 & 25082 & 0.32 & $0.32 \pm 0.77$ & $1.39 \pm 0.55$ \\
\hline & 371510 & 183 & 33639 & 0.50 & & \\
\hline & 88379 & 769 & 23291 & 0.15 & & \\
\hline \multirow[t]{3}{*}{5} & 396684 & 171 & 19924 & 2.27 & $1.02 \pm 1.08$ & $2.36 \pm 1.27$ \\
\hline & 145727 & 467 & 18730 & 0.43 & & \\
\hline & 128155 & 530 & 17536 & 0.37 & & \\
\hline \multirow[t]{3}{*}{6} & 148269 & 458 & 21500 & 0.22 & $0.25 \pm 0.85$ & $2.87 \pm 0.67$ \\
\hline & 141721 & 480 & 27271 & 0.28 & & \\
\hline & 137406 & 495 & 19112 & 0.24 & & \\
\hline \multirow[t]{3}{*}{8} & 22445 & 3030 & 7761 & 0.02 & $0.01 \pm 0.88$ & $0.33 \pm 0.11$ \\
\hline & 21833 & 3115 & 7960 & 0.01 & & \\
\hline & 27417 & 2480 & 10348 & 0.01 & & \\
\hline \multirow[t]{3}{*}{9} & 278184 & 244 & 41432 & 1.46 & $1.17 \pm 0.18$ & $4.32 \pm 1.86$ \\
\hline & 208067 & 327 & 21532 & 1.06 & & \\
\hline & 224561 & 303 & 42825 & 0.99 & & \\
\hline \multirow[t]{3}{*}{11} & 164852 & 412 & 41794 & 0.22 & $0.13 \pm 1.14$ & $1.38 \pm 0.67$ \\
\hline & 32059 & 2121 & 9954 & 0.04 & & \\
\hline & 120753 & 563 & 29058 & 0.13 & & \\
\hline
\end{tabular}

against weight, $W$, in a double logarithmic plot. Ingestion rates in this study were determined from the regression of Cammen (1980), which reflects a particular temperature regime $\left(-15^{\circ} \mathrm{C}\right)$ and animal size range. Experimental conditions in our study differed from those of Cammen; hence the exact relationship between weight and ingestion rate may differ.

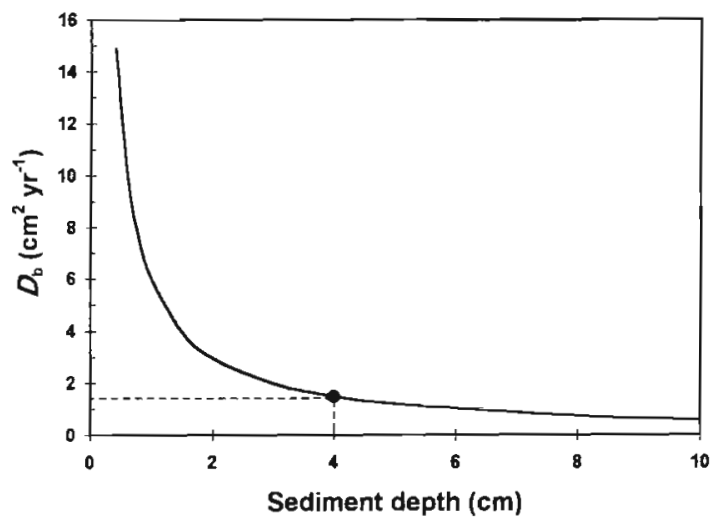

Fig. 2. Effect of sediment depth input on biodiffusion $\left(D_{\mathrm{b}}\right)$ rates in faunal-based biodiffusion model (Eq. 1) (Wheatcroft et al. 1990). Example calculated using mean core data from Box-cosm 3 and varying only sediment depth. (Dashed line: 4 cm reworking depth chosen)
To assess the sensitivity of the ingestion-based model and final $D_{\mathrm{b}}$ values to the weight parameter, one box-cosm (Box-cosm 3) was examined in detail with the 3 replicate animal data cores combined. The minimum and maximum weight ranges for all 30 species were used to set boundaries for this factor and to stretch $\Omega$ to the limit. Results showed that, using mini-

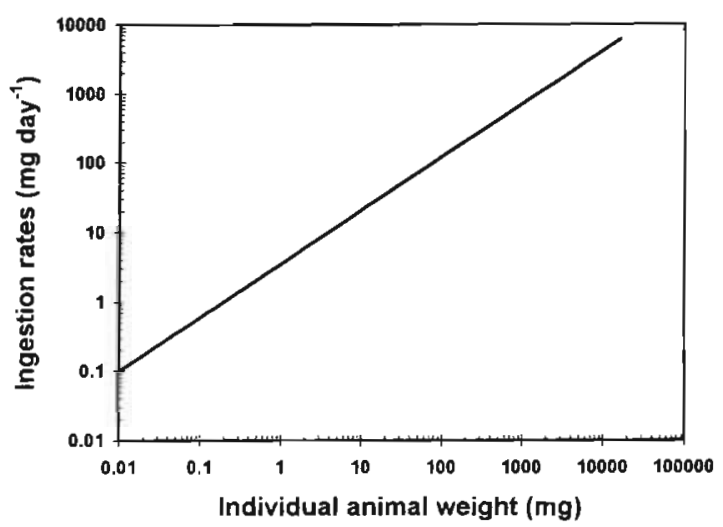

Fig. 3. Relationship between individual animal weight and ingestion rates for calculation of rest periods $(\Omega)$ in faunal-based biodiffusion model (Eq. 1) (Wheatcroft et al. 1990). Example used mean core organic matter and animal size-data from Box- $\operatorname{cosm} 3$ 
mum species weights, $\Omega$ was $>5$-fold higher, with a duration of $407 \mathrm{~d}$ compared to $73 \mathrm{~d}$ for maximum weights. The resulting range of $D_{\mathrm{b}} \mathrm{s}$ spanned from 0.36 to $2.01 \mathrm{~cm}^{2} \mathrm{yr}^{-1}$. This simply illustrates the high sensitivity of the ingestion model to natural fluctuations in animal weights. This range, however, did not include the measured $D_{\mathrm{b}}$ value for this box-cosm obtained by the tracer-based method $\left(4.5 \pm 0.7 \mathrm{~cm}^{2} \mathrm{yr}^{-1}\right)$.

\section{Influence of animal length on $D_{\mathrm{b}}$ estimates}

The distance that particles are moved or 'step lengths' were approximated using animal lengths. This parameter was measured directly from the faunal community samples, and thus is somewhat less ambiguous than $\Omega$. However, errors may still be incorporated into the calculations as this method of estimating step length is 1-dimensional and ignores horizontal mixing. Since $D_{b}$ rates are proportional to the square of the step length, the contribution to mixing by larger animals becomes increasingly important.

How the animal community affects biodiffusion

Analysis of ingestion rates and step-length estimates both conclude that large, deposit-feeding animals will nearly always dominate biogenous mixing. Results from the ${ }^{51} \mathrm{Cr}$-tracer measurements confirmed that the large deposit-feeding urchin Echinocardium cordatum did in fact dominate bioturbatory activities, with downward particle transport strongly correlated to E. cordatum abundance (Sandnes et al. 2000). This species dominated the faunal community in terms of size, thus displacing relatively large volumes of sediment per unit time and possibly over relatively long distances.

Wheatcroft et al. (1990) proposed that $D_{\mathrm{b}}$ rates are influenced more by size than by numbers of individuals. By assuming isometric growth (Esselink \& Zwarts 1989), an order of magnitude increase in body length produces an approximately $10^{4}$-fold increase in the per individual contribution to biodiffusivity. Also, Wheatcroft et al. pointed out that because biomass scales as $\mathrm{L}^{3}$, a 10 -fold increase in body length yields an approximately 20 -fold increase in mixing rates per unit biomass. This emphasises the important role of large deposit-feeders in sediment mixing.

The ingestion-based model (Eq. 1) used in the present study assumes that the bulk ingestion and subsequent egestion of particles in the sediment constitutes in nearly all cases the dominant mixing activity (Aller 1982, Thayer 1983). However, additional possible disturbance effects unrelated to feeding by (for example) the urchins have not been considered, and may pro- vide another explanation for under-estimation of biodiffusion processes by model predictions. These urchins are hard-bodied, sub-surface 'axial burrowers', which move sediment along their body with specially adapted appendages (Trueman \& Ansell 1969) and thus have significant impact on sediment-mixing.

This ingestion-based biodiffusion model using animal parameters did not consider physical diffusion rates. However, mean physical diffusion rates measured from the defaunated box-cosms were $0.28 \pm 0.05 \mathrm{~cm}^{2}$ $\mathrm{yr}^{-1}$ using the ${ }^{51} \mathrm{Cr}$ tracer (Sandnes et al. 2000), and therefore would not alone account for discrepancies between $D_{b}$ model estimates and tracer-based measurements.

\section{Sediment irrigation modelling}

Measured tracer $\left(\mathrm{Br}^{-}\right)$depth profiles and corresponding model predictions using animal parameters to estimate $\alpha$ for each box-cosm are presented in Fig. 4 . The incubation times for model simulation are indicated. Results show that in some box-cosms the model predicts irrigation processes well (Box-cosms 1, 5, 6 and 8), whereas in the other box-cosms, irrigation is over-estimated to different degrees by the model compared to measured $\mathrm{Br}^{-}$levels (Box-cosms 3, 4, 9 and 11).

\section{Sediment porosity $(\phi)$}

An exponential function (Eq. 4) was fitted to measured porosity-depth profiles, and best-fit values of parameters, $a, b$ and $c$ are shown in Table 2 . Sediment porosity is the only parameter in the non-local exchange term that varies as a function of depth and therefore determines the depth dependency of $\alpha(x)$ as proportional to $\phi^{2}(x)$ (Eq. 7 ).

\section{Radial-diffusion model parameters}

Model parameters $r_{1}, r_{2}, r^{*}$ and $R$ calculated from the animal community data and used in Eq. (6) are presented in Table 3.

$r_{1}$ is the inner radius of each cylinder, and was estimated as the mean width of all fauna within each box$\operatorname{cosm} ; r_{2}$ represents half the distance between the tube axes of individual organisms, and is therefore a mea. sure of the spacing between burrows (inversely proportional to animal abundance). The modelled animaldriven irrigation $(\alpha)$ is an increasing function of $r_{1}$ and a decreasing function of $r_{2}$ i i.e. higher irrigation rates result from both larger burrows and higher densities of animals, as expected. 


\section{BROMIDE CONCENTRATION $\left(\mu g l^{-1}\right)$}
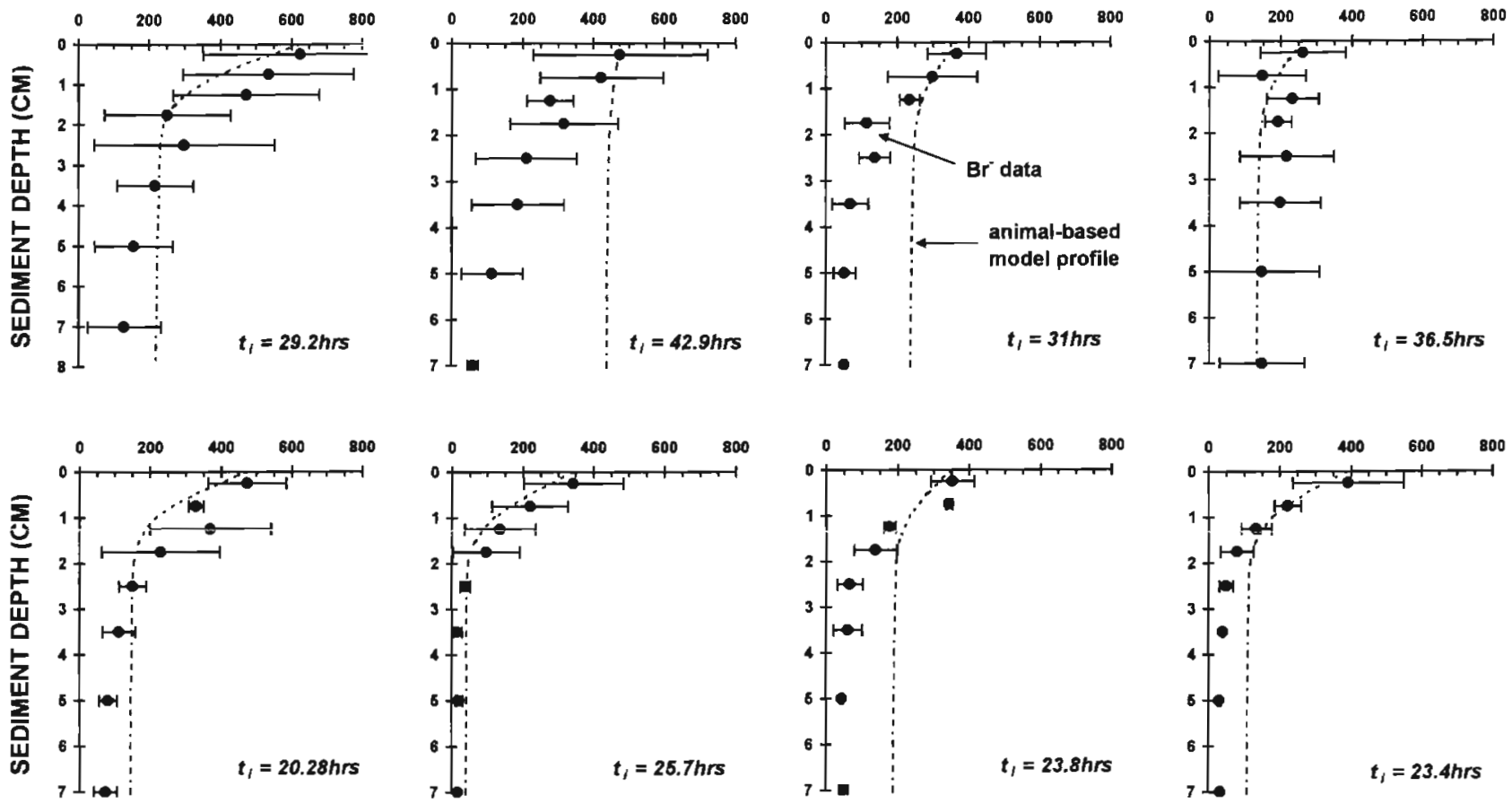

Fig. 4. Measured bromide depth profiles (data points) \pm SE and theoretical irrigation depth profiles calculated using faunal-based model (Eq. 3) (dashed line). Bromide incubation and model simulation times $\left(t_{j}\right)$ indicated for each box-cosm. Box-cosms are in numerical order: Box-cosms 1, 3, 4, 5 in top row, Box-cosms 6, 8, 9, 11 in lower row, from left to right

Sampling artifacts and natural patchiness in animal distributions may contribute to errors in $r_{1}$ and $r_{2}$. A $95 \%$ confidence range was therefore calculated for both parameters for one box-cosm (Box-cosm 1) to determine both natural variations within the box-cosm

Table 2. Best-fit of porosity parameters $a, b$ and $c$ in $\phi=a+b e^{-c x}$ for each box-cosm with replicates combined

\begin{tabular}{|ccccc|}
\hline Box-cosm no. & $a$ & $b$ & $c$ & $\begin{array}{c}\text { Correlation } \\
\text { coeff. (R) }\end{array}$ \\
\hline $\begin{array}{ccccc}\text { Faunated box-cosms } \\
1\end{array}$ & & & & \\
3 & 0.796 & 0.084 & 0.111 & 0.79 \\
4 & 0.829 & 0.069 & 0.380 & 0.80 \\
5 & 0.822 & 0.066 & 0.258 & 0.92 \\
6 & 0.824 & 0.071 & 0.220 & 0.98 \\
8 & 0.817 & 0.075 & 0.180 & 0.95 \\
9 & 0.830 & 0.069 & 0.725 & 0.88 \\
11 & 0.826 & 0.072 & 0.280 & 0.98 \\
Defaunated box-cosms & 0.812 & 0.083 & 0.244 & 0.97 \\
2 & 0.788 & 0.012 & 2.027 & 0.90 \\
7 & 0.790 & 0.012 & 1.436 & 0.94 \\
10 & 0.806 & 0.058 & 1.209 & 0.80 \\
12 & 0.829 & 0.069 & 0.380 & 0.80 \\
\hline
\end{tabular}

system and the sensitivity of this cylinder model to changes in $\Gamma_{1}$ and $\Gamma_{2}$. Fig. 5 illustrates predicted $\mathrm{Br}^{-}$profiles generated using $95 \%$ CIs for $r_{1}$ and $r_{2}$, respectively.

The $95 \%$ CIs for $r_{1}$ and $r_{2}$ represented ranges of 10 and $17 \%$ deviation from mean values, repectively. However, a much larger model deviation occurs for $r_{2}$ than for $r_{1}$, as shown in Fig. 5. This suggests that in our experimental range, irrigation depends more on abundance $\left(r_{2}\right)$ than on size $\left(r_{1}\right)$. This is also illustrated in Fig. 6, where $R$ (Eq. 8), is plotted as a function of $r_{1}$

Table 3. Radial-diffusion model parameters $r_{1}, r_{2}, r^{*}(\mathrm{~cm})$ and $R$ $\left(\mathrm{cm}^{-2}\right)$ calculated from faunal community data for each experimental box-cosm. Values are means \pm SD for replicate cores

\begin{tabular}{|c|c|c|c|c|}
\hline Box-cosm no & $r_{1}$ & $I_{2}$ & $r^{*}$ & $R$ \\
\hline 1 & $0.025 \pm 0.002$ & $0.39 \pm 0.05$ & $0.18 \pm 0.02$ & 1.03 \\
\hline 3 & $0.05 \pm 0.02$ & $0.35 \pm 0.04$ & $0.15 \pm 0.03$ & 4.41 \\
\hline 4 & $0.03 \pm 0.02$ & $0.34 \pm 0.05$ & $0.15 \pm 0.04$ & 2.49 \\
\hline 5 & $0.04 \pm 0.02$ & $0.42 \pm 0.03$ & $0.19 \pm 0.02$ & 1.56 \\
\hline 6 & $0.025 \pm 0.004$ & $0.38 \pm 0.03$ & $0.18 \pm 0.02$ & 1.15 \\
\hline 8 & $0.019 \pm 0.001$ & $0.61 \pm 0.05$ & $0.30 \pm 0.02$ & 0.18 \\
\hline 9 & $0.025 \pm 0.004$ & $0.31 \pm 0.06$ & $0.14 \pm 0.03$ & 2.17 \\
\hline 11 & $0.022 \pm 0.002$ & $0.39 \pm 0.15$ & $0.19 \pm 0.08$ & 0.87 \\
\hline
\end{tabular}


a)

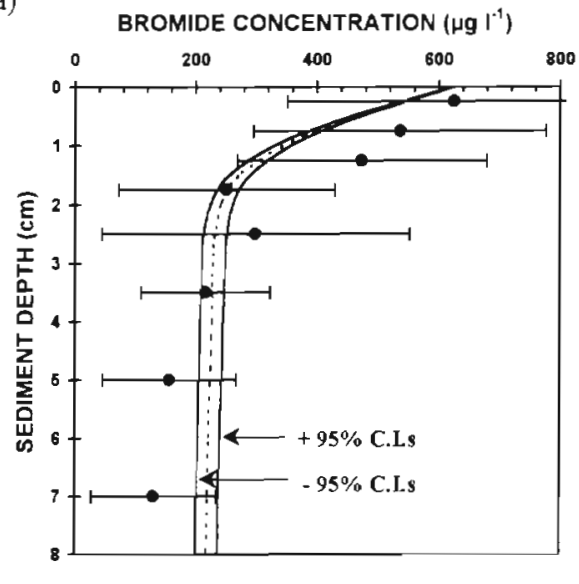

$r_{1} \pm 95 \%$ C.I.s and $r_{2}$ fixed b)

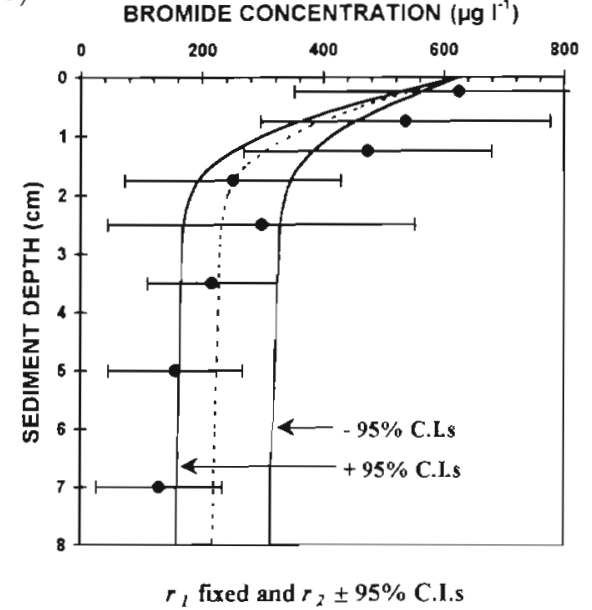

Fig. 5. Irrigation calculated using Eq. (3) superimposed on experimental $\mathrm{Br}^{-}$measurements, showing $95 \%$ CIs for burrow radius $\left(I_{1}\right)$ input (a), and showing $95 \% \mathrm{CIs}$ for average distance between burrows, $r_{2}(b)$ (upper axis) and $r_{2}$ (lower axis). Fig. 6 shows that $R$ decreases faster as a function of $r_{2}$, than it increases as a function of $r_{1}$. The 2 curves in this Fig. 6 indicate the $95 \%$ confidence range for the fixed parameters in each case.

It is also important to consider the validity of the radial-diffusion model for corresponding ranges of $r_{1}$ and $r_{2}$. The obvious physical constraint is for $r_{1}$ to be considerably smaller than $r_{2}$. In addition, the approximation, $r^{*} \approx\left(r_{2}-r_{1}\right) / 2$, introduces a singularity for $\alpha$ at $r_{1}=r_{2} / 3$, thus defining the upper limit of $r_{1}$ with respect to $r_{2}$.

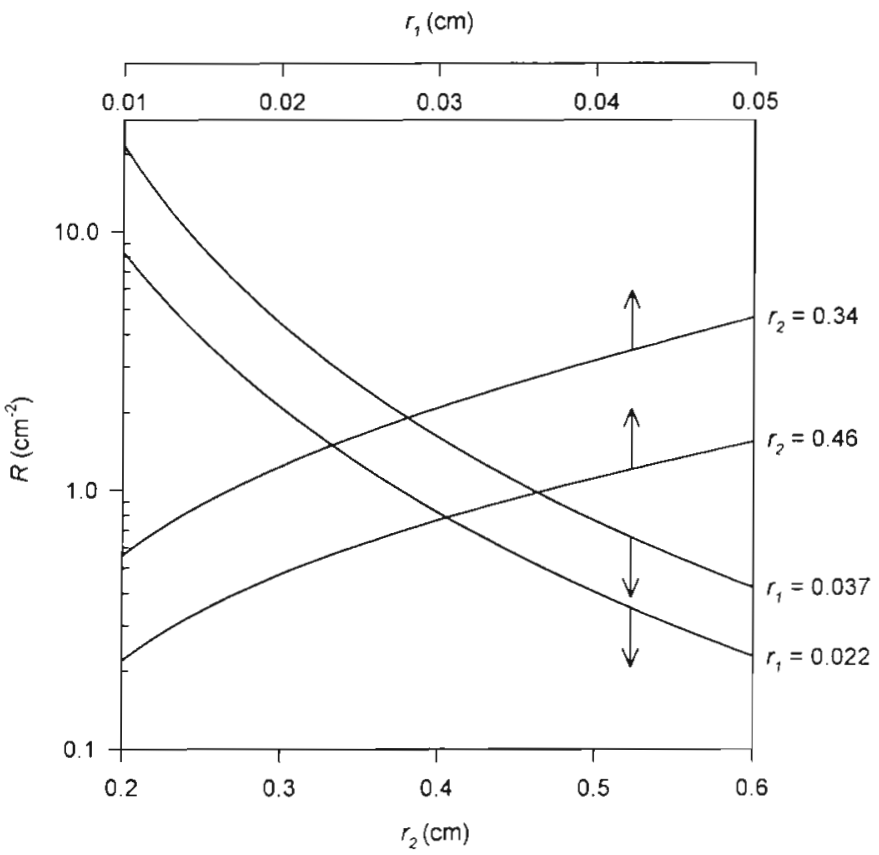

Fig. 6. $R$ (Eq. 8), determined by animal parameters, plotted as function of $r_{1}$ (upper axis) and $r_{2}$ (lower axis) for experimental data range. Curves indicate $95 \%$ conficence range for fixed parameter in each case
How the animal community affects irrigation

Benthic infauna may adopt different strategies to survive pore-water conditions in nearshore marine environments. Aller $(1980,1988)$ has suggested that animals may either build larger burrows or crowd together to reduce the build-up of noxious solutes such as ammonium in their environment. Commonly observed animal distributions reflect such adaptations. For example, early colonizers of defaunated bottoms, e.g. polluted sediments that contain high levels of interstitial metabolites, are characteristically tubedwellers and are densely crowded (Grassle \& Grassle 1974, Pearson \& Rosenberg 1978). This strategy is extremely efficient at lowering energy expenditure to maintain optimal burrow conditions. An alternative is to build large burrows. However, the low oxygen levels in such hostile, polluted environments together with the larger animals' low surface-to-volume ratio do not select for larger animals in such environments. These differences in adaptation to the environment lend support to the concept of succession in benthic communities (Pearson \& Rosenberg 1978, Aller 1980).

Boudreau \& Marinelli (1994) suggested additional strategies that may be adopted by macrofauna to optimize their burrow conditions. Infauna may benefit not only by reducing the inter-burrow distance, but also by increasing the amount of time spent irrigating. Although this may be controlled by individual species rhythms, living near to frequent irrigators would also be beneficial. This highlights the potential role of irrigation behaviour in structuring the composition of benthic environments.

Aller's (1980) study illustrates the influence of size and spacing of burrows on irrigation processes. One critical assumption of the radial-diffusion model applied in our study is that burrows are irrigated continuously and that burrow-water solute concentrations 
are constant at all times. However, many animals irrigate their burrows periodically in an on/off cycle (Boudreau \& Marinelli 1994), and hence modifications to this model to include irrigation behaviour may improve predictions.

The cylinder microenvironment model that has been applied in this study is an idealized depiction of diffusion-reaction geometries within the bioturbated zone (Aller 1980). The simplified nature of the model is one main advantage in enabling its practical application to the data usually available for marine ecosystems. A more complete model could include spatial and size distributions of species, residence times at particular depth levels, diffusion properties of burrow walls, and irrigation rates of individual species. However, given the simplicity of the model assumptions, the agreement between ineasured and predicted irrigation rates obtained in our study was relatively good.

\section{CONCLUSIONS}

Bioturbation and irrigation processes in natural sediments were investigated using faunal-based models and compared to results from experimental tracer measurements. The simple biodiffusion model of Wheatcroft et al. (1990) under-estimated bioturbation rates $\left(D_{\mathrm{b}}\right)$ compared with ${ }^{51} \mathrm{Cr}$-tracer measurements. The model predictions were highly sensitive to estimates of animal weight and sediment reworking depth. The model suggests that large, deposit-feeding animals dominate biogenous mixing and that mixing rates are more influenced by animal size than by density. In the box-cosm system, the large urchins Echinocardium cordatum did in fact dominate sediment-mixing processes, as discussed by Sandnes et al. (2000).

Model estimates of sediment-irrigation rates yielded varying results compared to those obtained by $\mathrm{Br}^{-}$ tracer measurements. In $50 \%$ of the box-cosms, the agreement between measured and predicted irrigation rates was good, although in the remainder, irrigation was over-estimated to different degrees. Modelled irrigation rates increased as a function of both burrow radius and animal density, with the strongest dependency on animal density. Over-estimated predictions may be attributable to the unrealistic model assumptions that all animals inhabit vertical burrows and irrigate them continuously.

Acknowledgements. This study was financially supported by The European Commission, as part of a post-doctoral TMR Marie Curie Research Training Fellowship (ERBFMBICT950496) awarded to J.S. Animal identification was undertaken at NIVA and financially supported by the State Pollu- tion Authority (SFT). Running expenses for bromide analysis was covered by Danish Science Council Grant 9503574 . We are grateful to Jørgen Noerrevang Jensen, who provided invaluable technical assistance, and Torsten Kälqvist for expert advice and assistance with the phytoplankton culture. Our thanks are extended to NIVA (Norwegian Institute for Water Research), for providing facilities at Solbergstrand Marine Station, Oslofjord, and NERI (National Environmental Research Institute), Denmark, for providing additional laboratory facilities.

\section{LITERATURE CITED}

Aller RC (1980) Quantifying solute distributions in the bioturbated zone of marine sediments by defining an average microenvironment. Geochim Cosmochim Acta 44:1955-1965

Aller RC (1982) The effects of macrobenthos on chemical properties of marine sediment and overlying water. In: McCall PL, Tevesz MJS (eds) Animal-sediment relations: the biogenic alteration of sediments, 2 nd Vol. Topics in geobiology. Plenum Press, New York, p 53-102

Aller RC (1983) The importance of the diffusive permeability of animal burrow linings in determining marine sediment chemistry. J Mar Res 41:299-322

Aller RC (1988) Benthic fauna and biogeochemical processes in marine sediments: the role of burrow structures. In: Blackburn TH, Sørensen J (eds) Nitrogen cycling in coastal marine environments. John Wiley \& Sons, Chichester, p 301-338

Bader RG (1954) Use of factors for converting carbon or nitrogen to total sedimentary organics. Science (NY) 120:709-710

Berner RA (1980) Early diagenesis: a theoretical approach. Princeton University Press, Princeton, NJ

Boudreau BP (1984) On the equivalence of nonlocal and radial-diffusion models for porewater irrigation. J Mar Res 42:731-735

Boudreau BP (1998) Mean mixed depth of sediments: the wherefore and the why. Limnol Oceanogr 43:524-526

Boudreau BP, Marinelli RL (1994) A modelling study of discontinuous biological irrigation. J Mar Res 52:947-968

Cammen LM (1980) Ingestion rate: an empirical model for aquatic deposit feeders and detritivores. Oecologia 44: $303-310$

Christensen JP, Devol AH, Smethie WM (1984) Biological enhancement of solute exchange between sediments and bottom water on the Washington continental shelf. Cont Shelf Res 3:9-23

Crank J (1975) Methods of solution when the diffusion coefficient is constant. In: The mathematics of diffusion. Clarendon Press, Oxford, p 11-27

Emerson S, Jahnke R, Heggie D (1984) Sediment-water exchange in shallow water estuarine sediments. J Mar Res 42:709-730

Esselink P, Zwarts L (1989) Seasonal trend in burrow depth and tidal variation in feeding activity of Nereis diversicolor. Mar Ecol Prog Ser 56:243-254

Gerino M, Aller RC, Lee C, Cochran JK, Aller JY, Green MA, Hirschberg D (1998) Comparison of different tracers and methods used to quantify bioturbation during a spring bloom: 234-thorium, luminophores, and chlorophyll $a$. Estuar Coast Shelf Sci 46:531-547

Grassle JF, Grassle JP (1974) Opportunistic life histories and genetic systems in marine polychaetes. J Mar Res 32: $253-284$

Hansen R, Forbes TL, Westermann P (1999) Importance of bioturbation and feeding by the polychaete Capitella 
species I in the degradation of di(2-ethylhexyl)phthalate (DEHP). Mar Ecol Prog Ser 182:187-199

Key RM, Brewer RL, Stockwell JH, Guinasso NL, Schink DR (1979) Some improved techniques for measuring radon and radium in marine sediments and in seawater. Mar Chem 7:251-264

Kristensen E (1988) Benthic fauna and biogeochemical processes in marine sediments: microbial activities and fluxes. In: Blackburn TH, Sørensen J (eds) Nitrogen cycling in coastal environments. John Wiley \& Sons Ltd, London, p 275-295

Li YH, Gregory S (1974) Diffusion of ions in seawater and deep sea sediments. Geochim Cosmochim Acta 38:703-714

Martin WR, Banta GT (1992) The measurement of sediment irrigation rates: a comparison of the $\mathrm{Br}^{-}$tracer and ${ }^{222} \mathrm{RN} /{ }^{226} \mathrm{RA}$ disequilibrium techniques. J Mar Res 50:125-154

Martin WR, Sayles FL (1987) Seasonal cycles of particle and solute transport processes in nearshore sediments: $\mathrm{Rn}-222 / \mathrm{Ra}-226$ and Th-234/U-238 disequilibrium at a site in Buzzards Bay, MA. Geochim Cosmochim Acta 51: 927-943

Pearson TH, Rosenberg R (1978) Macrobenthic succession in relation to organic enrichment and pollution of the marine environment. Oceanogr Mar Biol Annu Rev 16:229-311

Editorial responsibility: Otto Kinne (Editor),

Oldendort/Luhe, Germany
Powilleit M, Kitlar J, Graf G (1994) Particle and fluid bioturbation caused by the priapulid worm Halicryptus spinulosus (V. Seibold). Sarsia 79:109-117

Sandnes J, Forbes T, Hansen R, Sandnes B (2000) Influence of particle type and faunal activity on mixing of di(2-ethylhexyl)phthalate (DEHP) in natural sediments. Mar Ecol Prog Ser 197:151-167

Segerlind LJ (1984) Applied finite element analysis. John Wiley \& Sons, New York

Thayer CW (1983) Sediment-mediated biological disturbance and the evolution of marine benthos. In: Tevesz MJS, McCall PL (eds) Biotic interactions in recent and fossil communities. Plenum Press, New York, p 479-625

Trueman ER, Ansell AD (1969) The mechanism of burrowing into soft substrata by marine animals. Oceanogr Mar Biol Annu Rev 7:315-366

Wheatcroft RA, Jumars PA, Smith CR, Nowell ARM (1990) A mechanistic view of the particulate diffusion coefficient: step length, rest periods and transport directions. J Mar Res 48:177-207

Yingst JY, Rhoads DC (1980) The role of bioturbation in the enhancement of microbial turnover rates in marine sediments. In: Tenore KR, Coull BC (eds) Marine benthic dynamics. University of South Carolina Press, Columbia, p 407-422

Submitted: February 20, 1998; Accepted: October 26, 1999 Proofs received from author(s): March 30, 2000 